\title{
Sugar Sweetened Beverages Consumption among University Students of Bangladesh
}

\author{
Munmun Shabnam Bipasha', Tahsin Sharmila Raisa ${ }^{2}$, Shatabdi Goon ${ }^{3}$ \\ ${ }^{1,2}$ Business Administration, Daffodil International University, Bangladesh \\ ${ }^{3}$ Nutrition and Food Engineering, Daffodil International University, Bangladesh
}

\begin{tabular}{l}
\hline \hline Article Info \\
\hline Article history: \\
Received Mar 20, 2017 \\
Revised May 21, 2017 \\
Accepted May 30, 2017
\end{tabular}

Keywords:

Cross sectional study

Health education

Sugar sweetened beverages

University students

Weight gain

\begin{abstract}
Drinking large amounts of sugary beverages can increase the risk of gaining weight and developing Type 2 diabetes, heart disease, and other metabolic diseases. This study examined the preference, prevalence and pattern of sugar sweetened beverages consumption among university students of Bangladesh. A cross-sectional study was carried out from February to April, 2017 among students attending in a private university of Bangladesh. One hundred fifty undergraduates responded $(83.4 \%$ male, $15.9 \%$ female $)$ in this study. Most students (95.4\%) reported sugared beverage intake and 53.6\% reported more than two days in a week intake. Male students were more likely than female students to report regular sugary beverages intake $(85.4 \%$ vs. $14.5 \%)$. The main reasons for fast food consumption were: good taste and refreshing $(80.1 \%)$, cost effective (6.6\%), easy accessibility (2.6\%), increased convenience $(8.6 \%)$, and peer influence $(1.3 \%)$. Good taste and price were the most important factors in choosing beverages. Coca-Cola (49\%), Fanta (25.8\%), Sprite (9.9\%), and Slice (14.6\%) have been reported as mostly consumed beverages among students. Most students (54.5\%) reported sugary beverages purchase from neighborhood convenient stores. 94.5\% students said that if they would provide with healthful beverages within their food environment, they would prefer drinking healthful beverages (lemon water, non-sugary beverages) instead of sugar beverages. Self-reported sugar-sweetened beverage consumption among undergraduates is substantial and likely contributes considerable non-nutritive calories, which may contribute to weight gain. Specific health education programs, dietary guidelines and effective public awareness campaigns could be initiated to address the unhealthy drinking pattern of university students and improve their health.
\end{abstract}

Copyright $@ 2017$ Institute of Advanced Engineering and Science. All rights reserved.

\section{Corresponding Author:}

Shatabdi Goon,

Department of Nutrition and Food Engineering,

Daffodil International University,

Bangladesh.

Email: shatabdi.goon@gmail.com

\section{INTRODUCTION}

Over the last year, concerns about sugar-sweetened beverage (SSB) consumption and its impact on the obesity and chronic disease epidemic worldwide have taken center stage. [1] The prevalence of obesity has increased in the past 30 years, and at the same time a steep increase in consumption of soft drinks has been seen. Sugar sweetened beverages (SSBs), which include sodas and soft drinks as well as other beverages with caloric sweeteners (added sugars) such as fruit-flavored drinks, sports and energy drinks, and sweetened coffees and teas [2], are a major contributor of calories among young adults. Consumption of sugar-sweetened beverages (SSBs), particularly carbonated soft drinks, maybe a key contributor to the 
epidemic of overweight and obesity, by virtue of these beverages' high added sugar content, low satiety, and incomplete compensation for total energy [3]. SSBs are considered high-glycemic index liquids that increase post-prandial blood glucose levels, decrease insulin sensitivity, and decrease satiety levels-resulting in overeating [4]. Prior research on SSB intake in adults and children has linked its consumption with obesity, diabetes, and several demographics such as race, gender, age, and socioeconomic background. The majority of the prospective studies found positive associations between intake of calorically sweetened beverages and obesity [5]. In a meta-analysis of 88 studies, an association between soft drink consumption and increased energy intake and body weight has been found [6]. In a separate study, increased consumption of SSBs was associated with higher total and abdominal obesity in US adults aged 20-39 years [7]. The higher intake of SSBs was linked to higher energy intake, added sugars and carbohydrates, as well as a lower intake of fiber, orange juice, and low fat milk and with an increased risk of several medical problems (e.g., diabetes, obesity) [6-8]. Although there are limited studies regarding SSB by young adults attending college, those that exist propose that a majority of students consume SSBs. West et al (2009) found that $95 \%$ of college students reported consuming SSBs in the past month and $65 \%$ of students consume SSBs on a daily basis. Further, men were more frequent consumers compared to women [9]. Increased portion sizes and fast food consumption are typical dietary behaviors of college students; these factors have been linked to increased SSB consumption. In the past 30 years, SSB consumption has increased in all ages from multiple sources including vending machines, restaurants, fast-food establishments, and grocery stores and supermarkets [10].

The purpose of this study was to examine sugar sweetened beverage intake patterns among university students. Specifically, this study will explore the days per week SSBs are consumed and factors associated with sugar sweetened beverages consumption. The specific aims of this study are to: a) examine the daily and weekly SSB consumption patterns by young adults attending university; b) examine the relationship between ages, gender, body weight, height with SSB consumption patterns; c) explore the factors associated with sugary beverages consumption. The question that has been examined in this study are: 1) Why do you drink SSBs? Do you drink SSBs for their taste appeal, availability, or pricing? 2) Do you wish to either decrease your SSB consumption or live a healthier lifestyle? 3) Do you understand the health consequences associated with drinking SSBs. 4) If you would provide with healthful beverages instead of sugar sweetened beverages, which one you would prefer.

It is ostensible that young adults are vulnerable to weight gain and weight gain while attending college can be significant. Various interrelated factors impact the health and health behaviors and attitudes of this age group. It is important to recognize the contribution of SSBs to calories and sugars that lead to this weight gain and resulting health concerns. If consumption patterns exceed recommendations, reducing SSB intake may be one simplistic behavior change to impact dietary behaviors to reduce obesity prevalence among young. By promoting healthful dietary patterns in college students, healthier lifestyle patterns are established in adulthood and perhaps future generations. Little of the research on SSB intake has examined consumption patterns of SSBs by college students, despite the vulnerabilities of this population to weight gain [11]. This study addressed some of these gaps and limitations by focusing on SSB consumption by young adults, specifically university students.

\section{MATERIALS AND METHODS}

A cross-sectional study was carried out from February to April, 2017 among students attending one established private university of Bangladesh situated in Dhanmondi, Dhaka: Daffodil International University. A total number of one hundred and fifty university students within the ages of 18 to 24 were randomly selected from this institution. Undergraduate students at the Daffodil International University at Dhaka, Bangladesh, were approached at the beginning of class and offered an opportunity to volunteer for an anonymous survey. Students who were regular with their class schedule were included in the study, and those who were not regular in that sense were excluded. 126 male students and 24 female students were selected for the interview. All the selected students were made well informed of the study aims and verbal consent was taken for their participation in the study. Interviews were conducted in the classroom and the varsity canteen while they were enjoying their class break. A semi-structured questionnaire was used to collect data regarding age, sex, self-reported weight and height, pocket money per month, meal patterns, sugar sweetened beverages preference, sugar sweetened beverages consumption per week, monthly expenditure on sugar sweetened beverages, sources of sugar sweetened beverages, the cause behind the consumption of sugar sweetened beverages, health complications. 


\section{RESULTS AND ANALYSIS}

Mean age of the respondents was 21 years. A total of 144 (95.4\%) students reported their preference for sugar sweetened beverages as shown in Table 2 and approximately $53.6 \%$ of the respondents mentioned that they consumed sugar sweetened beverages more than two days a week. Male students were more habituated with sugar sweetened beverages consumption compared to female students as shown in Table 6 . 123 of the male students $(85.4 \%)$ preferred sugar sweetened beverages where $21(14.5 \%)$ of female students reported about their preference. The type of sugar sweetened beverages they preferred included Coca-Cola (49\%), Fanta (25.8\%), Sprite (9.9\%) and Slice (14.6\%). Average daily caloric intake associated with reported sugared beverages among college students was $560 \mathrm{kcal} / \mathrm{d}$ (4 to $5 \mathrm{servings} /$ day across the combined types of sugared beverages) as shown in Table 3. The main reasons for sugar sweetened beverages consumption were: good taste and refreshing $(80.1 \%)$, cost effective (6.6\%), easy accessibility $(2.6 \%)$, increased convenience $(8.6 \%)$, and peer influence $(1.3 \%)$. Most of the students reported to possess around Tk. 3000 in pocket money per month and spent around Tk. 500 of that on sugar sweetened beverages i.e. $16.7 \%$ of their pocket money was spent on sugar sweetened beverages each month. Neighborhood convenient stores/outlets and the varsity canteen or local shop were reported to be popular sugar sweetened beverages sources by $54.3 \%$ and $45.7 \%$ respondents respectively as shown in Table 5. Approximately 95.6\% were aware that sugar sweetened beverages contain large amounts of sugar and calories as shown in Table 4. 94.5\% students said that they would prefer healthful beverages instead of sugar sweetened beverages if they would provide with those options within their food environment as shown in Table 7. Table 1 shows the detailed habits and patterns of sugar sweetened beverages consumption of the respondents.

Table 1. Characteristics of Respondents and its Relationship with Sugar Sweetened Beverages Consumption

\begin{tabular}{|c|c|}
\hline Characteristics/ Beverages & Respondents \\
\hline \multicolumn{2}{|l|}{ Gender } \\
\hline Male & $126(83.4 \%)$ \\
\hline Female & $24(15.9)$ \\
\hline \multicolumn{2}{|l|}{ Sugar Beverage Preference by gender } \\
\hline Male & $123(85.4 \%)$ \\
\hline Female & $21(14.5 \%)$ \\
\hline \multicolumn{2}{|l|}{ Sugar Beverage Preference by respondents } \\
\hline Yes & $144(95.4 \%)$ \\
\hline No & $6(4 \%)$ \\
\hline \multicolumn{2}{|l|}{ Sugar Beverage Consumption ( day/week) ( n- 150) } \\
\hline 1 day/week & $37(24.5 \%)$ \\
\hline 2 days/week & $32(21.2 \%)$ \\
\hline More than 2 days/week & $81(53.6 \%)$ \\
\hline \multicolumn{2}{|l|}{ Reason of Sugar Beverage consumption ( $n-150$ ) } \\
\hline You feel good and refreshed & $121(80.1 \%)$ \\
\hline It is cost effective & $10(6.6 \%)$ \\
\hline It is available & $4(2.6 \%)$ \\
\hline Convenient/Easy access & $13(8.6)$ \\
\hline Your friends ask to drink ( peer influence) & $2(1.3 \%)$ \\
\hline \multicolumn{2}{|l|}{ Types of Beverages consumed $(n-150)$} \\
\hline Fanta & $39(25.8 \%)$ \\
\hline Coca Cola & $74(49 \%)$ \\
\hline Sprite & $15(9.9 \%)$ \\
\hline Slice & $22(14.6 \%)$ \\
\hline \multicolumn{2}{|l|}{ Place of Purchasing Sugar Beverage ( $\mathrm{n}-150)$} \\
\hline Local Shop & $68(45 \%)$ \\
\hline Market & $82(54.3 \%)$ \\
\hline \multicolumn{2}{|c|}{ If provided, preferences for Healthful Drink Consumption $(n-150)$} \\
\hline Yes & $143(94.7 \%)$ \\
\hline No & $7(4.6 \%)$ \\
\hline
\end{tabular}

Table 2. Sugar Sweetened Beverage Preferences by Respondents

\begin{tabular}{cccccc}
\hline & \multicolumn{5}{c}{ Do you take sugar sweetened beverages? } \\
& & Frequency & Percent & Valid Percent & Cumulative Percent \\
\hline Valid & no & 6 & 4.0 & 4.0 & 4.0 \\
& yes & 144 & 95.4 & 96.0 & 100.0 \\
& Total & 150 & 99.3 & 100.0 & \\
Missing & System & 1 & .7 & & \\
Total & & 151 & 100.0 & & \\
\hline
\end{tabular}


Table 3. Types of Sugar Beverages Consumed by Respondents

\begin{tabular}{cccccc}
\hline & & \multicolumn{3}{c}{ Which beverages do you prefer most? } \\
& & Frequency & Percent & Valid Percent & Cumulative Percent \\
\hline Valid & Fanta & 39 & 25.8 & 26.0 & 26.0 \\
& Coca cola & 74 & 49.0 & 49.3 & 75.3 \\
& Sprite & 15 & 9.9 & 10.0 & 100.3 \\
& slice & 22 & 14.6 & 14.7 & \\
Missing & Total & 150 & 99.3 & 100.0 & \\
Total & System & 1 & .7 & & \\
\hline
\end{tabular}

Table 4. Point-of -Purchase by Respondents

\begin{tabular}{llcccc}
\hline & & \multicolumn{3}{c}{ From where do you purchase sugar beverages? } & \\
& & Frequency & Percent & Valid Percent & Cumulative Percent \\
\hline Valid & local shop & 68 & 45.0 & 45.3 & 45.3 \\
& market & 82 & 54.3 & 54.7 & 100.0 \\
& Total & 150 & 99.3 & 100.0 & \\
Missing & System & 1 & .7 & \\
Total & & 151 & 100.0 & \\
\hline
\end{tabular}

Table 5. Factors Associated with Sugar Beverages Consumption by Respondents

\begin{tabular}{|c|c|c|c|c|c|}
\hline \multicolumn{6}{|c|}{ Why do you like to drink sugar beverages? } \\
\hline & & Frequency & Percent & Valid Percent & Cumulative Percent \\
\hline \multirow[t]{6}{*}{ Valid } & you feel good and refreshed & 121 & 80.1 & 80.7 & 80.7 \\
\hline & it is cost effective & 10 & 6.6 & 6.7 & 87.3 \\
\hline & it is available & 4 & 2.6 & 2.7 & 90.0 \\
\hline & convenient/easy access & 13 & 8.6 & 8.7 & 98.7 \\
\hline & $\begin{array}{l}\text { your friends ask to drink ( peer } \\
\text { influence) }\end{array}$ & 2 & 1.3 & 1.3 & 100.0 \\
\hline & Total & 150 & 99.3 & 100.0 & \\
\hline Missing & System & 1 & .7 & & \\
\hline Total & & 151 & 100.0 & & \\
\hline
\end{tabular}

Table 6. Weekly Consumption Pattern of Sugar Beverages by Respondents

\begin{tabular}{llcccc}
\hline & \multicolumn{4}{c}{ How many times per week? } \\
& & Frequency & Percent & Valid Percent & Cumulative Percent \\
\hline Valid & 1 & 37 & 24.5 & 24.7 & 24.7 \\
& 2 & 32 & 21.2 & 21.3 & 46.0 \\
& more than 2 & 81 & 53.6 & 54.0 & 100.0 \\
& Total & 150 & 99.3 & 100.0 & \\
Missing & System & 1 & .7 & \\
Total & & 151 & 100.0 & \\
\hline
\end{tabular}

Table 7. If Provided with Healthful Beverages, Preference for those Instead of Sugar Beverages by Respondents

\begin{tabular}{|c|c|c|c|c|c|}
\hline \multicolumn{6}{|c|}{$\begin{array}{c}\text { If you would provide with other health drinks, do you prefer to drink those instead of sugar } \\
\text { beverages? }\end{array}$} \\
\hline & & Frequency & Percent & Valid Percent & Cumulative Percent \\
\hline \multirow[t]{3}{*}{ Valid } & no & 7 & 4.6 & 4.7 & 4.7 \\
\hline & yes & 143 & 94.7 & 95.3 & 100.0 \\
\hline & Total & 150 & 99.3 & 100.0 & \\
\hline Missing & System & 1 & .7 & & \\
\hline Total & & 151 & 100.0 & & \\
\hline
\end{tabular}

\section{DISCUSSION}

Over the past 30 years, there has been a marked increase in consumption of SSBs across the globe. [12] To date, many studies have evaluated the relationship between SSB consumption and weight gain or risk of overweight and obesity among adults. For instance, in the US, intake of these beverages which includes the full range of soft drinks, fruit drinks, energy and vitamin water drinks increased from $3.9 \%$ of calories in the late 1970 's to $50.6 \%$ in 2013 , representing a 17 -fold increase in intake $[13,14]$. 
This paper reports sugar sweetened beverages consumption habits in young people attending one established private university in Bangladesh. The findings showed that sugar sweetened beverages consumption is becoming more common, and the number of visits to university canteen, neighborhood fast food restaurants, local convenient stores that are the most common sources of sugar sweetened beverages is growing even more rapidly. Sugar sweetened beverages are especially popular among the younger generation. Most of the university students prefer sugary beverages. Undergraduate reported substantial sugared beverage consumption, with fully $95.4 \%$ reporting regular consumption and $53.6 \%$ reporting more than two days week consumption. Average daily caloric intake associated with reported sugared beverages among college students was $560 \mathrm{kcal} / \mathrm{d}$ (4 to 5 servings/d across the combined types of sugared beverages). Thus, concerns that sugar-sweetened beverages may represent a significant source of energy consumption that could contribute to weight gain and escalating obesity rates among children and adolescents [15-17] should clearly be extended to undergraduate populations.

Preference for sugar sweetened beverages among young people and adolescents was also found in other countries [8-10]. In a study, most students $(95 \%)$ reported sugared beverage intake in the past month, and $65 \%$ reported daily intake [8]. Similarly in our study, most students (95.4\%) reported sugared beverage intake and $53.6 \%$ reported daily consumption in this study. In a study, Men reported significantly higher intake of sugar-sweetened beverages than women $(74 \%$ vs. $61 \%, p=0.035)$, with almost one-half of male college students reporting that they consumed soda daily and one-third reporting consumption of two or more sugar sweetened sodas daily [8]. This higher level may reflect what can be assumed to be higher body weights or may reflect a proportionally higher intake than that seen among women. Studies of younger adolescents have also reported greater soda intake among men than women, even when accounting for differences in body weight $[18,19]$. In our study, male students were more likely than female students to report regular sugary beverages intake $(85.4 \%$ vs. $14.5 \%)$. In a study, soda was the most common sugarsweetened beverage that had been reported by college students [8]. In our study, Coca-Cola (49\%), Fanta $(25.8 \%)$, Sprite $(9.9 \%)$ and Slice $(14.6 \%)$ has been reported as mostly consumed beverages among students.

In a study, mean estimated caloric intake from combined types of sugar-sweetened beverages was $543 \mathrm{kcal} / \mathrm{d}$. In this study, average daily caloric intake associated with reported sugared beverages among university students was $560 \mathrm{kcal} / \mathrm{d}$ (4 to 5 servings/d across the combined types of sugared beverages). Recent interventions to reduce soda consumption among children have shown initial efficacy in reducing obesity levels [20] and may provide helpful models that can be extended to weight gain prevention efforts targeted at college-age populations. Weight gain prevention programs have not been empirically examined in undergraduate populations, although weight gain among students in college is common [21-23], and weight gain during young adulthood may be particularly detrimental to later health [24]. 94.5\% students said that if they would provide with healthful beverages within their food environment, they prefer drinking healthful beverages (lemon water, non-sugary beverages) instead of sugar beverages. Thus, a weight gain prevention program that focused on reductions in sugared beverage consumption might be attractive to undergraduate students.

In this study, most students $(54.5 \%)$ reported sugary beverages purchase from neighborhood convenient stores. Environmental interventions to reduce availability of sugared soda have also been suggested for children and adolescents $[25,26]$. Such approaches merit consideration for university campuses also. Modifications to point-of-purchase messages in a university food service setting have been shown to have a beneficial impact on food purchases [27], indicating that altering college environments to reduce exposure to sugared-sweetened beverages holds promise for decreasing intake of sugar-sweetened beverages. A study conducted by Islam \&Ul-lah [28] identified brand reputation, accessibility, taste, cost, quality, food hygiene, and fat and cholesterol level as the factors related to fast food and soft drinks preferences by the university students in Bangladesh. Similarly, in our study, the main reasons for sugar sweetened beverages consumption were: good taste and refreshing (80.1\%), cost effective (6.6\%), easy accessibility (2.6\%), increased convenience $(8.6 \%)$, and peer influence $(1.3 \%)$.

Sugar sweetened beverages are energy dense foodstuffs that are heavily marketed to adolescents, and are likely to be important in terms of risk of obesity [29]. A dramatic increase in diabetes and other obesity related diseases has been observed in parallel with sugar sweetened beverages consumption [30, 31]. In the long run, this will increase healthcare costs and will stretch the limited available resources allocated to healthcare. Moreover, students spent approximately one third of their pocket money on sugar sweetened beverages, which put extra economic burden on the parents of the university students. It was indicated in this study that most of the sugar sweetened beverages consumers are well informed about the negative effects associated with consumption, but they were still reported to have sugar sweetened beverages at a regular basis without considering their health complications. The younger generations are getting addicted to sugar sweetened beverages, which indicates a serious public health concern and urgent action should be taken to tackle this public health problem [32-34]. 


\section{STUDY LIMITATION}

Our study has several limitations. The data was self -reported and the study is cross-sectional which does not infer causal relationships. Furthermore, we examined only one private university in the Capital city; this data should only be generalized cautiously for public universities or universities outside Dhaka city.

\section{CONCLUSION}

Obesity and associated health co-morbidities are a serious public health concern. Sugar sweetened beverages, typically containing sucrose, high-fructose corn syrup, or fruit juice concentrates, may lead to weight gain through the high added sugar content, low satiety, and potential incomplete compensation for total energy, leading to increased energy intake. Educating young university students to limit SSB intake and practice other healthy behaviors could significantly impact their physical and mental health. Specific health education programs, dietary guidelines and effective public awareness campaigns could be initiated to address the unhealthy lifestyle of university students and to improve their health. A combined initiative from families, universities, public health experts and the government is much needed to tackle this public health problem. University food outlets should be encouraged to provide a greater range of healthy beverages for the students.

\section{ACKNOWLEDGEMENTS}

We would like to thanks our honorable professors, colleagues and friends for supporting us to initiate the study subject. We are also grateful to those students who cooperated with us to conduct the interview.

\section{REFERENCES}

[1] J. A. Welsh, et al., "The sugar-sweetened beverage wars: public health and the role of the beverage industry," Curr Opin Endocrinol Diabetes Obes, vol/issue: 20(5), pp. 401-406, 2013.

[2] Institute of Medicine, "Accelerating progress in obesity prevention: solving the weight of the nation," Washington, DC: National Academies of Science, 2012.

[3] Malik V. S., et al., "Intake of sugar-sweetened beverages and weight gain: a systematic review," Am J Clin Nutr., vol. 84, pp. 274-288,2006.

[4] Olsen N. J. and Heitmann B. L., "Intake of calorically sweetened beverages and obesity," Obes Rev, vol. 10, pp. $68-75,2009$

[5] Schulze M. B., et al., "Sugar-sweetened beverages, weight gain, and incidence of type 2 diabetes in young and middle-aged women," J Am Med Assoc., vol. 292, pp. 927-934,2004.

[6] Vartanian L. R., et al., "Effects of soft drink consumption on nutrition and health: a systematic review and metaanalysis," Am J Public Health, vol. 97, pp. 667-675, 2007.

[7] P. Mirmiran, et al., "Consumption of sugar sweetened beverage is associated with incidence of metabolic syndrome in Tehranian children and adolescents," NutrMetab (Lond), vol. 12, pp. 25, 2015.

[8] West D. S., et al., "Self-reported sugar-sweetened beverage intake among college students," Obesity (Silver Spring), vol/issue: 14(10), pp. 1825-31, 2006.

[9] C. D. Rehm, et al., "Demographic and behavioral factors associated with daily sugar-sweetened soda consumption in New York City adults," Journal of Urban Health: Bulletin of the New York Academy of Medicine, vol/issue: 85(3), pp. 375-384, 2008.

[10] S. Harrington, "The role of sugar-sweetened beverage consumption in adolescent obesity: A review of literature," The Journal of School Nursing, 2008.

[11] https://kb.osu.edu/dspace/handle/1811/54653

[12] V. S. Malik, et al., "Sugar sweetened beverages, obesity, type 2 diabetes and cardiovascular disease risk," Circulation, vol/issue: 121(11), pp. 1356-1364, 2010.

[13] Kit B. K., et al., "Trends in sugar-sweetened beverage consumption among youth and adults in the United States: 1999-2010," Am J ClinNutr, vol. 98, pp. 180-8, 2013.

[14] Rivera J. A., et al., "Consumo de bebidas para unavidasaludable: Recomendaciones para la población (Beverage consumption for a healthy life: recommendations for the Mexican population)," Salud Publica Mexico, vol. 50, pp. 173-195, 2008.

[15] Dietz W., "Sugar-sweetened beverages, milk intake, and obesity in children and adolescents," J Pediatr, vol. 148, pp. 152- 4, 2006.

[16] Berkey C. S., et al., "Sugar-added beverages and adolescent weight change," Obes Res., vol. 12, pp. 778 - 88, 2004.

[17] Troiano R., et al., "Energy and fat intakes of children and adolescents in the United States: Data from the National Health and Nutrition Examination Surveys," Am J ClinNutr., vol. 72, pp. 1343-53S, 2000.

[18] Forshee R. A. and Storey M. L., "Total beverage consumption and beverage choices among children and 
adolescents," Int J Food SciNutr, vol. 54, pp. 297-307, 2003.

[19] Harnack L., et al., "Soft drink consumption among US children and adolescents: Nutritional consequences," $J A m$ Diet Assoc, vol. 99, pp. 436 - 41, 1999.

[20] James J., et al., "Preventing childhood obesity by reducing consumption of carbonated drinks: Cluster randomised controlled trial," BMJ, vol. 328, pp. 1237, 2004.

[21] Levitsky D. A., et al., "The freshman weight gain: A model for the study of the epidemic of obesity," Int J Obes Relat Metab Disord, vol. 28, pp. 1435- 42, 2004.

[22] Racette S. B., et al., "Weight changes, exercise and dietary patterns during freshman and sophomore years of college," J Am Coll Health, vol. 53, pp. 245-51,2005.

[23] Anderson D. A., et al., "The freshman year of college as a critical period for weight gain: an initial evaluation," Eat Behav, vol. 4, pp. 363-7, 2003.

[24] Williamson D., et al., "The 10-y incidence of obesity and major weight gain in black and white US women aged 30-55 y," Am J Clin Nutr, vol. 53, pp. 1515- 8S, 1991.

[25] Berkey C. S., et al., "Sugar-added beverages and adolescent weight change," Obes Res., vol. 12, pp. 778 - 88, 2004.

[26] Harnack L., et al., "Soft drink consumption among US children and adolescents: nutritional consequences," $J$ Am Diet Assoc, vol. 99, pp. 436 - 41, 1999.

[27] Buscher L. A. and Martin K. A., "Point-of-purchase messages framed in terms of cost, convenience, taste, and energy improve healthful snack selection in a college food service setting," J Am Diet Assoc, vol. 101, pp. 909-13, 2001.

[28] Islam N. and Ullah G. M. S., "Factors affecting consumers' preferences on fast food items in Bangladesh," J Applied Business Research, vol. 26, pp. 131-46, 2010.

[29] Denney W. E., et al., "Influences on consumption of soft drinks and fast foods in adolescents," Asia Pac J ClinNutr, vol/issue: 18(3), pp. 447-52, 2009.

[30] Popkin B., "The nutrition transition and obesity in the developing world," $J$ Nutr, vol/issue: 131(3), pp. 871S-873S, 2001.

[31] Yadav K. and Krishnan A., "National Prevalence of Obesity: Changing patterns of diet, physical activity and obesity among urban, rural and slum populations in north India," Obes Rev, vol/issue: 9(5), pp. 400-8, 2008.

[32] Colic B. I., et al., "Nutritive value of meals, dietary habits and nutritive status in Croatian university students according to gender," Int J Food Sci Nutr, vol. 54, pp. 473-84, 2003.

[33] Yadav K. and Krishnan A., "National Prevalence of Obesity: Changing patterns of diet, physical activity and obesity among urban, rural and slum populations in north India," Obes Rev, vol/issue: 9(5), pp. 400-8, 2008.

[34] Denney W. E., et al., "Influences on consumption of soft drinks and fast foods in adolescents," Asia Pac J Clin Nutr, vol/issue: 18(3), pp. 447-52, 2009. 